\title{
BMJ Open Value of age and alarm features for predicting upper gastrointestinal malignancy in patients with dyspepsia: an endoscopic database review of 4664 patients in Thailand
}

\author{
Uayporn Kaosombatwattana (D) ,1,2 Phunchai Charatcharoenwitthaya (D) ,,2 \\ Nonthalee Pausawasdi (D) , 1,2 Monthira Maneerattanaporn, ${ }^{1,2}$ Julajak Limsrivilai, ${ }^{1,2}$ \\ Somchai Leelakusolvong, ${ }^{1,2}$ Udom Kachintorn ${ }^{1,2}$
}

To cite: Kaosombatwattana U, Charatcharoenwitthaya $P$, Pausawasdi N, et al. Value of age and alarm features for predicting upper gastrointestinal malignancy in patients with dyspepsia: an endoscopic database review of 4664 patients in Thailand. BMJ Open 2021;11:e052522. doi:10.1136/ bmjopen-2021-052522

- Prepublication history for this paper is available online To view these files, please visit the journal online (http://dx.doi. org/10.1136/bmjopen-2021052522).

Received 19 April 2021 Accepted 12 0ctober 2021

Check for updates

(c) Author(s) (or their employer(s)) 2021. Re-use permitted under CC BY-NC. No commercial re-use. See rights and permissions. Published by BMJ.

${ }^{1}$ Gastroenterology Division, Department of Medicine, Faculty of Medicine Siriraj Hospital, Mahidol University, Bangkok, Thailand

${ }^{2}$ Siriraj Gl Endoscopy Center, Faculty of Medicine Siriraj Hospital, Mahidol University, Bangkok, Thailand

Correspondence to Professor Phunchai Charatcharoenwitthaya; phunchai@yahoo.com

\section{ABSTRACT}

Objective Age and alarm features are commonly used as indicators for endoscopy in dyspeptic patients; however, the age cut-off and the predictive value of these parameters for identifying upper gastrointestinal (UGI) malignancies are uncertain.

Design Cross-sectional study.

Setting Data were extracted from the Gastrointestinal Endoscopy Centre of Siriraj Hospital, Thailand, during 2005-2011.

Participants Consecutive patients underwent a firsttime upper endoscopy for dyspepsia. Patients with previous surgery, suspected UGI malignancy by imaging, or indefinite biopsy results on prior examination were excluded.

Main outcome measures Alarm features included dysphagia, unintentional weight loss, Gl bleeding/anaemia and persistent vomiting. The diagnostic performance of each alarm feature and different age cut-off values were evaluated.

Results A total of 4664 patients (mean age: $52.0 \pm 14.4$ years, $66 \%$ female) were included. Alarm symptoms were presented in $21.6 \%$. The prevalence of active Helicobacter pylori infection was $26.3 \%$. Fifty-eight (1.2\%) patients had UGI malignancy. The prevalence of malignancy significantly increased with increasing age $(0.6 \%$ in patients aged $<50$ years, and $1.8 \%$ in patients aged $>60$ years $(p<0.001))$. Cancer was found in two patients aged $<50$ years who did not have alarm features. Patients with alarm features had a higher prevalence of malignancy (OR $22.3,95 \% \mathrm{Cl} 10.5$ to $47.4 ; \mathrm{p}<0.001$ ) than those without. The pooled sensitivity, specificity, positive predictive value and negative predictive value of alarm features for UGI malignancy were $87.0 \%, 79.1 \%, 4.7 \%$ and $99.8 \%$, respectively. Among all age groups, persistent vomiting had a positive likelihood ratio $(P L R)>10$, while dysphagia and Gl bleeding/anaemia had a PLR $>10$ in patients $<50$ years old.

Conclusion Despite the overall limited value of age and alarm features, persistent vomiting, dysphagia, and Gl bleeding/anaemia are strong predictors for malignancy in patients aged $<50$ years. Without these symptoms, cancer
Strengths and limitations of this study

- The value of age and alarm features for predicting upper gastrointestinal malignancies among patients with dyspepsia is limited.

- Alarm features, such as dysphagia, gastrointestinal bleeding/anaemia and persistent vomiting, are strong clinical predictors of underlying upper gastrointestinal malignancy in patients aged $<50$ years, so endoscopic evaluation in these patients is indicated.

- The data analysed among different age groups are derived from a large number of patients with dyspepsia. Therefore, they are likely to be representative of diverse populations.

- It is possible that this study has some selection bias. Because it was conducted at a tertiary, referred centre, this could lead to biased estimates of the prevalence of malignancies and other organic dyspepsia causes.

prevalence is negligible; thus, they are worthy guidance for endoscopic evaluation in this age group.

\section{INTRODUCTION}

Dyspepsia is a common gastrointestinal (GI) disorder that is reported to affect $20 \%$ of the global population, ${ }^{1}$ and it accounts for $2 \%-5 \%$ of all consultations in a primary care setting. ${ }^{2}$ Upper GI (UGI) malignancies are an uncommon cause for dyspepsia, but they are the greatest concern among patients and physicians. Current dyspepsia guidelines recommend that the decision to perform endoscopy be based on older age status and the presence of alarm features because these predictive parameters have traditionally been thought to be associated with more serious organic pathology, especially underlying malignancy. ${ }^{3-5}$ 
Several studies from Asian ${ }^{6-12}$ and Western populations $^{1314}$ that evaluated the diagnostic accuracy of alarm features and age threshold for predicting underlying malignancy in dyspeptic patients have been published. The sensitivity of alarm features for the prediction of UGI malignancy varied from $0 \%$ to $83 \%$ with considerable heterogeneity among studies, and the specificity also significantly varied from $40 \%$ to $98 \% .^{15}$ A systematic review of studies in the Asian population reported an overall malignancy detection rate in dyspeptic patients of $1.3 \%$, and the proportion of younger cancer patients was high. ${ }^{16}$ The diagnostic accuracy of alarm features for predicting UGI malignancy was found to be moderate, and the optimal age threshold for endoscopy screening in Asia might be 35 years. ${ }^{16}$ However, the occurrence of gastric cancer varies markedly among Asian countries due to differences in the background prevalence of Helicobacter pylori infection. ${ }^{17}$ Thus, the alarm features and age threshold values for predicting underlying malignancy in dyspeptic patients may vary among distinct geographic regions, and this suggests that patients from different parts of the world may need to be managed differently.

Accordingly, this study aimed to investigate the detection rate of UGI malignancies in a large cohort of Thai patients with dyspepsia who underwent endoscopy performed in clinical practice, and estimate the diagnostic accuracy of alarm features and age threshold for predicting malignancy in this Asian patient population.

\section{METHODS}

\section{Study population}

This retrospective study analysed data from the Gastrointestinal Endoscopy Centre of Siriraj Hospital, Mahidol University, Bangkok, Thailand. The study protocol conformed to the ethical guidelines of the 1975 Helsinki Declaration. Consecutive outpatients aged $>18$ years who underwent a first endoscopic evaluation for uninvestigated dyspepsia during 2005-2011 were included in the analysis. Exclusion criteria included the following: (1) dysphagia in the absence of dyspeptic symptoms; (2) prior gastric surgery; (3) indefinite biopsy results on prior endoscopic examination and (4) suspected GI malignancy by imaging before performing endoscopy. The following data were obtained for the analysis: demographics, clinical details of unhealthy lifestyles (eg, alcohol consumption and cigarette smoking), a family history of UGI cancer in the first-degree relatives, dyspeptic symptoms, alarm features, the indication for endoscopy and the endoscopic and histological findings. The requirement for written informed consent from patients was waived given the retrospective design of the study.

\section{Definitions}

Dyspepsia was defined as one or more symptoms of epigastric pain, epigastric burning, postprandial fullness and/ or early satiety for at least 3 months. ${ }^{18}$ The following were considered to be alarm symptoms in this study: dysphagia, weight loss, GI bleeding or anaemia and persistent vomiting. Dysphagia was defined as the perception of an impediment to the passage of swallowed material. Unexplained weight loss was defined as a $5 \%$ or $10 \%$ loss in body weight during the past 3 or 6 months, respectively. GI bleeding was defined as any evidence of haematemesis or melena. Anaemia was defined as haemoglobin level during dyspepsia episodes less than $120 \mathrm{~g} / \mathrm{L}$ and $130 \mathrm{~g} / \mathrm{L}$ in women and men, respectively.

Gastro-oesophageal reflux disease (GERD) was defined as mucosal breaks or erosions within the oesophagus as graded by the Los Angeles classification. ${ }^{19}$ Barrett's oesophagus was diagnosed if there was evidence of intestinal metaplasia in tissue taken above the gastrooesophageal junction. The presence of dysplasia and grading was confirmed by pathological evaluation. An ulcer was defined as a mucosal defect larger than $5 \mathrm{~mm}$ in diameter. Ulcer size and location were recorded. Gastritis, duodenitis, vascular lesions, portal hypertension-related lesions (including oesophageal/gastric varices and portal hypertensive gastropathy), and gastric or duodenal polyps were identified. Active $H$. pylori infection was determined by using a rapid urease test or histology from endoscopic biopsy specimens.

For patients with suspected UGI malignancy on endoscopy, the confirmatory diagnosis was made by histological examination from biopsy or surgical specimens. UGI malignancy comprises oesophageal cancer (squamous cell carcinoma and adenocarcinoma), gastric cancer (adenocarcinoma, lymphoma, mucosa-associated lymphoid tissue and GI stromal tumour) and proximal small bowel malignancy, including periampullary cancer.

\section{Patient and public involvement}

No patient and public involved in this study.

\section{Statistical analysis}

Data were summarised using descriptive statistics. Continuous variables were compared using Student's t-test, and categorical variables were compared using the $\chi^{2}$ test. Logistic regression was used to identify patients' characteristics and alarm symptoms that discriminated patients with the structural disease on upper endoscopy from those who did not. Receiver operating characteristic (ROC) curves were constructed to assess the overall accuracy of individual and pooled alarm features for predicting UGI malignancies. The predictive ability of alarm features for differentiating between patients with and without UGI malignancies was further analysed by calculation of sensitivity, specificity, positive likelihood ratio (PLR), negative likelihood ratio (NLR), positive predictive value (PPV) and negative predictive value (NPV) with 95\% CI. The numbers of patients and endoscopic findings of malignancy according to different age groups were calculated. The age group breakdown was $<40$ years, 40-49 years, 50-59 years and $\geq 60$ years because, according to a review of guidelines for dyspepsia management, the current American ${ }^{4}$ and Thai guidelines ${ }^{3}$ set the cut-off 
Table 1 Baseline characteristics of the total cohort and compared among age groups

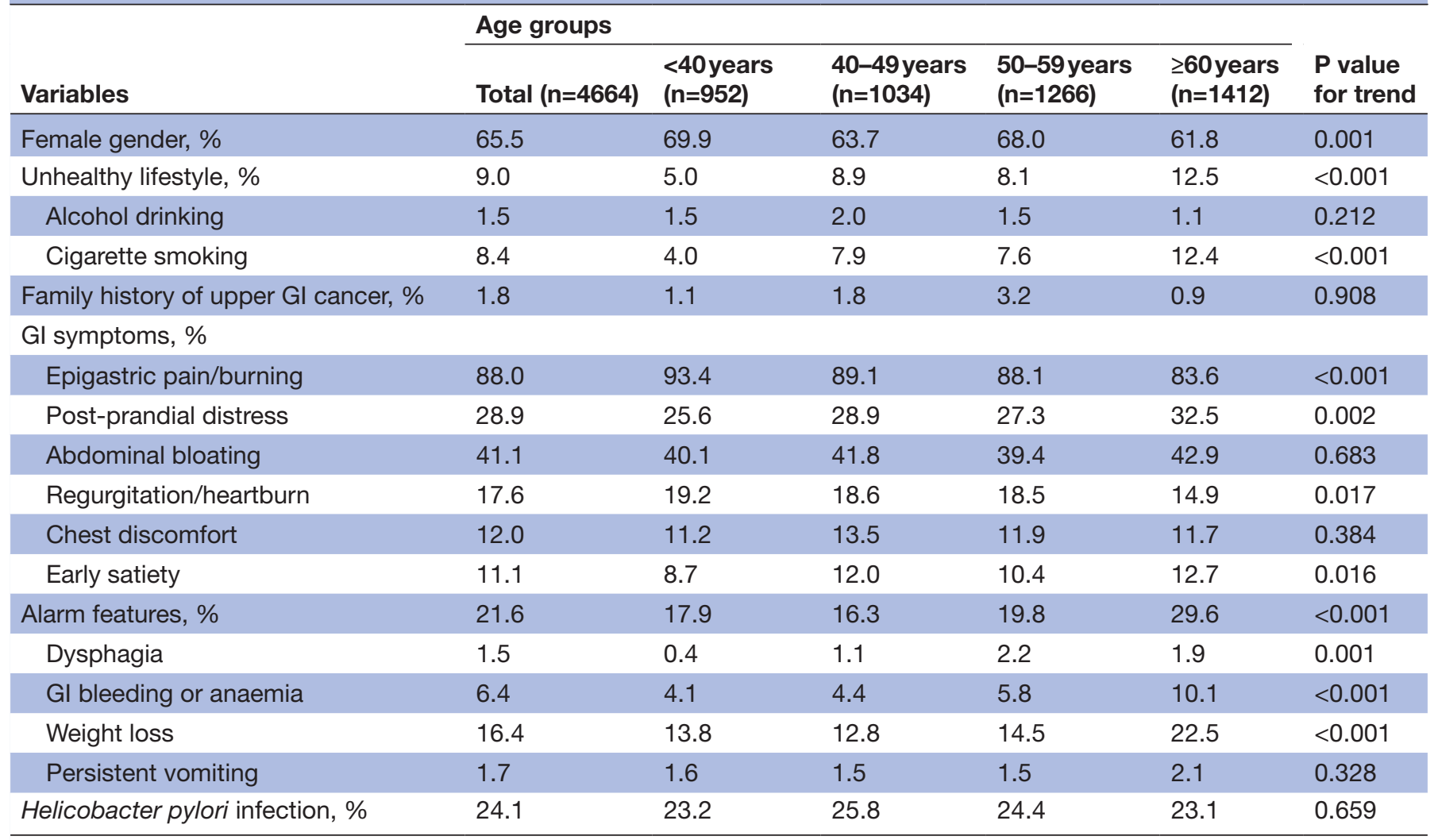

Data are presented as the percentage of patients with an each condition among age groups.

Unhealthy lifestyle was defined as alcohol drinking and/or previous/current smoking.

A $p<0.05$ indicates statistical significance.

Gl, gastrointestinal.;

age threshold for endoscopy at 60 and 50 years, respectively. Moreover, Asian guidelines recommend endoscopy for those aged 35-55 years, depending on the risk of gastric cancer in the region where the patient lives. ${ }^{5}$ SPSS 18.0 software (SPSS, Chicago, Illinois, USA) was used to perform all statistical analyses, and a two-tailed $\mathrm{p}<0.05$ was considered to be statistically significant.

\section{RESULTS}

\section{Patient population}

During the 7-year study period, 5104 patients underwent first-time diagnostic upper endoscopy for which dyspepsia was indicated. A total of 440 patients were excluded for various reasons, and the remaining 4664 patients were included in this study. Table 1 shows the baseline characteristics of the total study cohort and compared among age groups. The mean age was $52.6 \pm 14.3$ years (range: $18-98$ ), and female patients accounted for $66 \%$. Older patients were more frequently to have unhealthy lifestyles, especially previous or current smoking, than younger patients. The reported prevalence of a family history of UGI cancer was similar among the different age groups. Among 3376 patients evaluated for $H$. pylori, the infection rate was $26.3 \%$ (95\% CI $24.9 \%$ to $27.8 \%$ ). Alarm symptoms were present in $21.6 \%$ of the overall patient population. The predominant indications for endoscopy among the 3657 patients without alarm symptoms were, as follows: abdominal pain or discomfort $(\mathrm{n}=2622,71.7 \%)$, regurgitation or heartburn $(\mathrm{n}=501,13.7 \%)$, chest discomfort $(\mathrm{n}=274,7.5 \%)$, abdominal bloating $(\mathrm{n}=222,6.1 \%)$ and early satiety $(\mathrm{n}=38,1 \%)$.

\section{Endoscopic findings among the different age groups and individual alarm features}

Prevalence estimates of endoscopic findings for the entire cohort and compared among age groups are shown in table 2. Overall, 55 patients were diagnosed with pathologically confirmed UGI malignancies, including 4 oesophageal, 47 gastric and 4 duodenal malignancies. None of 83 dyspeptic patients with a family history of gastric cancer had UGI malignancy on the endoscopic evaluation. The prevalence of UGI malignancy significantly increased from $1.2 \%$ in patients aged $40-50$ years to $1.8 \%$ in patients aged $\geq 60$ years $(p<0.001)$, and 5 patients with UGI malignancy were younger than 45 years. Cancer was found in two $(0.1 \%)$ of 1641 patients aged $<50$ years who did not have alarm features. The prevalence of peptic ulcers increased from $2.1 \%$ in patients aged $<40$ years to $7.4 \%$ in patients aged $\geq 60$ years $(\mathrm{p}<0.001)$, and $34.9 \%$ of patients with peptic ulcer disease were infected with $H$. pylori. Similarly, the prevalence of erosive/haemorrhagic 
Table 2 Prevalence estimates of endoscopic findings for the entire cohort and compared among age groups

Percentage $(95 \% \mathrm{Cl})$ of endoscopic finding among age groups

\begin{tabular}{|c|c|c|c|c|c|c|}
\hline \multirow[b]{2}{*}{$\begin{array}{l}\text { Endoscopic } \\
\text { findings }\end{array}$} & & \multirow[b]{2}{*}{$\begin{array}{l}\text { P value } \\
\text { for trend }\end{array}$} \\
\hline & Total $(n=4664)$ & $<40$ years $(n=952)$ & $\begin{array}{l}40-49 \text { years } \\
(n=1034)\end{array}$ & $\begin{array}{l}50-59 \text { years } \\
(n=1266)\end{array}$ & $\geq 60$ years $(n=1412)$ & \\
\hline GI malignancy & 1.2 (0.9 to 1.5$)$ & 0.0 (0 to 0$)$ & $1.2(0.7$ to 2.0$)$ & 1.3 (0.8 to 2.1$)$ & 1.8 (1.3 to 2.7$)$ & $<0.001$ \\
\hline $\begin{array}{l}\text { Barrett's } \\
\text { oesophagus }\end{array}$ & 0.5 (0.3 to 0.7$)$ & 0.2 (0.05 to 0.7$)$ & 0.5 (0.2 to 1.1$)$ & 0.3 (0.1 to 0.8$)$ & 0.8 (0.4 to 1.4$)$ & 0.073 \\
\hline Peptic ulcer & 4.6 (4.1 to 5.3$)$ & 2.1 (1.4 to 3.2 ) & 3.4 (2.5 to 4.7 ) & 4.5 (3.5 to 5.8$)$ & 7.4 (6.1 to 8.9$)$ & $<0.001$ \\
\hline $\begin{array}{l}\text { Erosive/ } \\
\text { haemorrhagic } \\
\text { gastritis/ } \\
\text { duodenitis }\end{array}$ & 17.7 (16.6 to 18.8 ) & 10.8 (9.0 to 13.0$)$ & 17.1 (14.9 to 19.6$)$ & 18.8 (16.7 to 21.1$)$ & 21.8 (19.7 to 24.0$)$ & $<0.001$ \\
\hline $\begin{array}{l}\text { Gastroduodenal } \\
\text { polyp }\end{array}$ & 4.6 (3.8 to 5.5$)$ & 2.0 (1.2 to 3.6$)$ & 3.9 (2.7 to 5.8$)$ & 5.2 (3.9 to 6.4 ) & 6.1 (4.8 to 8.1$)$ & $<0.001$ \\
\hline
\end{tabular}

Data are presented as the percentage $(95 \% \mathrm{Cl})$ of patients with an endoscopic finding.

A $p<0.05$ indicates statistical significance.

Gl, gastrointestinal.

gastroduodenitis increased from $10.8 \%$ in patients aged $<40$ years to $21.8 \%$ in patients aged $\geq 60$ years $(\mathrm{p}<0.001)$. The prevalence of GERD non-significantly increased from $7.9 \%$ in patients aged $<40$ years to $10.8 \%$ in patients aged $\geq 60$ years $(p=0.132)$. In addition, the prevalence of Barrett's oesophagus was very low in all age groups, ranging from $0.2 \%$ in patients aged $<40$ years to $0.8 \%$ in patients aged $\geq 60$ years $(p=0.172)$.
Table 3 shows the prevalence estimates of endoscopic findings relative to alarm features. Patients with alarm features had a higher prevalence of UGI malignancy (OR 22.3, 95\% CI 10.5 to 47.4; $\mathrm{p}<0.001$ ), peptic ulcer (OR 2.40, 95\% CI 1.80 to $3.20 ; \mathrm{p}<0.001$ ) and erosive/ haemorrhagic gastroduodenitis (OR 1.24, 95\% CI 1.03 to $1.48 ; \mathrm{p}=0.02$ ) compared with those without alarm symptoms. Patients with dysphagia had significantly higher

Table 3 Prevalence estimates for endoscopic findings relative to alarm features

\begin{tabular}{|c|c|c|c|c|c|c|}
\hline \multirow[b]{2}{*}{$\begin{array}{l}\text { Endoscopic } \\
\text { findings }\end{array}$} & \multicolumn{6}{|c|}{ Percentage $(95 \% \mathrm{Cl})$ of endoscopic finding among alarm features } \\
\hline & $\begin{array}{l}\text { No alarm } \\
\text { features }(n=3657)\end{array}$ & $\begin{array}{l}\text { Alarm feature } \\
(n=1007)\end{array}$ & Dysphagia $(n=68)$ & $\begin{array}{l}\text { Weight loss } \\
\text { ( } n=759)\end{array}$ & $\begin{array}{l}\text { GI bleeding/ } \\
\text { Anaemia }(n=298)\end{array}$ & Vomiting $(n=78)$ \\
\hline Erosive oesophagitis & 10.0 (9.0 to 11.0$)$ & $8.7(7.1$ to 10.7$)$ & $19.4(11.4$ to 30.9$)$ & $8.6(6.8$ to 10.9$)$ & $7.6(5.0$ to 11.3$)$ & $12.9(6.7$ to 23.4$)$ \\
\hline Barrett's oesophagus & $0.5(0.3$ to 0.8$)$ & $0.3(0.1$ to 0.9$)$ & $0.0(0$ to 0$)$ & $0.4(0.1$ to 1.2$)$ & $0.4(0.1$ to 2.0$)$ & $0.0(0$ to 0$)$ \\
\hline Oesophageal ulcer & $0.5(0.3$ to 0.7$)$ & $0.7(0.4$ to 1.5$)$ & $3.2(0.9$ to 11.0$)$ & $0.6(0.2$ to 1.4$)$ & $1.4(0.6$ to 3.7$)$ & $1.6(0.3$ to 8.6$)$ \\
\hline $\begin{array}{l}\text { Erosive/ } \\
\text { haemorrhagic } \\
\text { gastritis/duodenitis }\end{array}$ & $17.0(15.8$ to 18.3$)$ & $20.2(17.8$ to 22.9$) \dagger$ & $17.7(10.2$ to 29.0$)$ & 18.9 (16.2 to 21.9$)$ & $21.7(17.2$ to 26.9$)$ & $27.4(17.9$ to 39.6$)$ \\
\hline $\begin{array}{l}\text { Non-erosive } \\
\text { gastritis/duodenitis }\end{array}$ & 44.8 (43.2 to 46.4$)$ & 38.9 (35.8 to 42.0$) \dagger$ & 32.3 (22.0 to 44.6$)$ & 39.7 (36.1 to 43.3 ) & 36.8 (31.4 to 42.6$)$ & 41.9 (30.5 to 54.3$)$ \\
\hline
\end{tabular}

Data are presented as the percentage $(95 \% \mathrm{Cl})$ of patients with an endoscopic finding.

${ }^{*} \mathrm{P}<0.001$ for comparison between patients with and without alarm features.

$\dagger P=0.001$ for comparison between patients with and without alarm features.

$\mathrm{Gl}$, gastrointestinal. 
rates of malignancy $(\mathrm{p}<0.001)$ and erosive oesophagitis $(p<0.001)$ than those without this symptom. The rates of malignancy and peptic ulcer were significantly higher in dyspeptic patients with weight loss, persistent vomiting and GI bleeding or anaemia than in those who did not (all $\mathrm{p}<0.05$ ).

In dyspeptic patients who had no evidence of structural disease to explain weight loss or GI bleeding/anaemia on upper endoscopy, further evaluation was performed selectively based on the type of ongoing symptoms. Of these, 427 patients who continued dyspeptic symptoms with alarm features or concomitant intestinal symptoms underwent additional colonoscopy. Colorectal cancer was identified in 18 patients $(4.2 \%)$, of whom $13(72.3 \%)$ were older than 50 years old.

\section{Factors associated with UGI malignancy}

In univariate logistic regression analysis, the presence of UGI malignancy on upper endoscopy was significantly associated with age $(\mathrm{p}<0.001)$, previous or current smoking $(\mathrm{p}=0.011)$, dysphagia $(\mathrm{p}<0.001)$, weight loss $(p<0.001)$, GI bleeding/anaemia $(p<0.001)$ and persistent vomiting $(\mathrm{p}<0.001)$. In multivariate analysis, age and four-alarm features remained independent predictors of UGI malignancy: age (OR 1.02, 95\% CI 1.01 to $1.05 ; \mathrm{p}=0.034$ ), dysphagia (OR $7.04,95 \% \mathrm{CI} 2.54$ to 19.5; $\mathrm{p}<0.001$ ), weight loss (OR 11.4, 95\% CI 5.70 to 23.0; $\mathrm{p}<0.001$ ), GI bleeding/anaemia (OR 5.16, $95 \%$ CI 2.77 to 9.63; $\mathrm{p}<0.001)$ and persistent vomiting (OR 10.4, 95\% CI 5.06 to $21.4, \mathrm{p}<0.001)$.

\section{Diagnostic performance of individual alarm features in the different age groups}

Among 1007 patients with alarm features, 47 (4.7\%) were found to have UGI cancer. The pooled sensitivity, specificity, PPV and NPV of alarm features for predicting malignancy were $87.0 \%, 79.1 \%, 4.7 \%$ and $99.8 \%$, respectively (table 4). Among the four-alarm features, unexplained weight loss had the highest sensitivity $(79.6 \%)$ and the lowest PPV (5.7\%), whereas dysphagia had the lowest sensitivity (11.1\%) and a low PPV (8.8\%). All of the four-alarm features had high specificity (range: $84.4 \%$ to 98.7\%) and very high NPV (range: 98.9\%-99.7\%). After calculating the PLR and NLR of these alarm features separately and in different age groups, we found persistent vomiting to have a PLR $>10$ in all age groups. Dysphagia and GI bleeding/anaemia among patients aged $<50$ years had a PLR $>10$, while weight loss among all age groups had a PLR $<10$. All four-alarm features in the different age groups had an NLR ranging from 0.20 to 0.94 (table 5).

Among 391 patients with previous/current smoking, 10 $(2.6 \%)$ were found to have UGI malignancy. In patients with this unhealthy lifestyle, dysphagia and persistent vomiting had a PLR $>10$, while GI bleeding/anaemia and weight loss had a PLR $<10$, regardless of the age group (table 6). All four-alarm features had PPVs for predicting malignancy ranging from $11.8 \%$ to $30.0 \%$ and remained very high NPVs of $>98 \%$.

\section{DISCUSSION}

This study revealed the values of age threshold and alarm features for identifying dyspeptic patients at risk for UGI malignancy. We found that UGI malignancy occurred in $1.2 \%$ of patients with dyspepsia who underwent endoscopy, and the prevalence of cancer significantly increased from $0.6 \%$ in patients aged $<50$ years to $1.8 \%$ in patients aged $>60$ years. No malignancy was found in patients aged $<40$ years. Approximately one-fifth of dyspeptic patients who underwent endoscopy had alarm features, and only $4.7 \%$ of those were found to have UGI malignancies. The pooled sensitivity, specificity, PPV and NPV of alarm features for predicting UGI cancer were $87.0 \%$, $79.1 \%, 4.7 \%$ and $99.8 \%$, respectively. These findings indicate that age and alarm features are not strongly suggestive of underlying UGI malignancy. However, among dyspeptic patients aged $<50$ years, individual alarm features, except weight loss, had a PLR $>10$ for UGI cancer prediction.

We describe a large Thai cohort who underwent endoscopic evaluation for dyspepsia in clinical practice. The data provide information about organic causes of dyspepsia that should be relevant to patient care, such as malignancy, peptic ulcer disease, complicated oesophagitis (ulcers and Barrett's metaplasia), and the typing and

\begin{tabular}{|c|c|c|c|c|c|}
\hline Features & AUROC $(95 \% \mathrm{Cl})$ & Sensitivity $(95 \% \mathrm{Cl})$ & Specificity $(95 \% \mathrm{Cl})$ & PPV $(95 \% \mathrm{Cl})$ & NPV $(95 \% \mathrm{Cl})$ \\
\hline Dysphagia & 0.55 (0.53 to 0.56$)$ & 11.1 (4.2 to 22.6 ) & 98.7 (98.3 to 99.0$)$ & 8.8 (4.2 to 17.6$)$ & 98.9 (98.8 to 99.0 ) \\
\hline Weight loss & 0.82 (0.81 to 0.83 ) & 79.6 (66.5 to 89.4$)$ & 84.4 (83.3 to 85.4$)$ & 5.7 (4.9 to 6.5$)$ & 99.7 (99.5 to 99.8 ) \\
\hline Gl bleeding/anaemia & 0.67 (0.66 to 0.69$)$ & 40.7 (27.6 to 55.0$)$ & 94.0 (93.3 to 94.7$)$ & 7.4 (5.4 to 10.1$)$ & 99.3 (99.1 to 99.4) \\
\hline Vomiting & $0.64(0.63$ to 0.66$)$ & 29.6 (18.0 to 43.6$)$ & 98.7 (98.3 to 99.0$)$ & 20.5 (13.8 to 29.4$)$ & 99.2 (99.0 to 99.3 ) \\
\hline Overall & 0.83 (0.82 to 0.84$)$ & 87.0 (75.1 to 94.6$)$ & 79.1 (77.8 to 80.2$)$ & 4.7 (4.2 to 5.2$)$ & 99.8 (99.6 to 99.9 ) \\
\hline
\end{tabular}

The AUROC curve, sensitivity, specificity, PPV and NPV of individual alarm feature were calculated to discriminate between dyspeptic patients with and without upper GI malignancy.

The histopathological examination from endoscopic biopsy or surgical specimens with diagnosing upper Gl malignancies served as the reference group.

AUROC, area under the receiver operating characteristic curve; NPV, negative predictive value; PPV, positive predictive value. 
Table 5 Diagnostic performance of alarm features for predicting upper GI malignancies in the different age groups

\begin{tabular}{|c|c|c|c|c|c|}
\hline Alarm features & Age groups & PLR (95\% CI) & NLR $(95 \% \mathrm{CI})$ & PPV (95\% Cl) & NPV $(95 \% \mathrm{Cl})$ \\
\hline \multirow[t]{3}{*}{ Dysphagia } & $<50$ years & 11.7 (1.7 to 82.1$)$ & $0.92(0.8$ to 1.1$)$ & 6.7 (1.0 to 33.4$)$ & 99.4 (99.3 to 99.5$)$ \\
\hline & $50-60$ years & 9.66 (3.2 to 28.9) & 0.83 (0.7 to 1.0$)$ & 11.1 (4.0 to 27.2 ) & 98.9 (98.7 to 99.2$)$ \\
\hline & Overall & 8.21 (3.7 to 18.2$)$ & 0.90 (0.8 to 1.0$)$ & 8.8 (4.2 to 17.6$)$ & 98.9 (98.8 to 99.0$)$ \\
\hline \multirow[t]{3}{*}{ Weight loss } & $<50$ years & 5.81 (4.1 to 8.2$)$ & 0.29 (0.1 to 0.8$)$ & 3.4 (2.4 to 4.8$)$ & 99.8 (99.5 to 99.9$)$ \\
\hline & $\geq 60$ years & 3.98 (3.3 to 4.8$)$ & 0.20 (0.08 to 0.5$)$ & 7.0 (5.8 to 8.3$)$ & 99.6 (99.1 to 99.9$)$ \\
\hline & Overall & 5.09 (4.4 to 5.9$)$ & $0.24(0.1$ to 0.4$)$ & 5.7 (4.9 to 6.5$)$ & 99.7 (99.5 to 99.8 ) \\
\hline \multirow[t]{3}{*}{ GI bleeding/anaemia } & $<50$ years & 12.7 (6.9 to 23.2) & 0.52 (0.3 to 0.9$)$ & 7.1 (4.0 to 12.4 ) & 99.7 (99.4 to 99.8$)$ \\
\hline & $50-60$ years & 5.82 (2.7 to 12.5$)$ & 0.73 (0.5 to 1.0$)$ & 6.9 (3.4 to 13.8$)$ & 99.1 (98.7 to 99.3 ) \\
\hline & $\geq 60$ years & 4.48 (2.8 to 7.2 ) & 0.64 (0.5 to 0.9 ) & 7.7 (5.0 to 11.9) & 98.8 (98.4 to 99.1$)$ \\
\hline \multirow{3}{*}{ Persistent vomiting } & 50-60 years & 20.6 (7.7 to 55.3) & $0.76(0.6$ to 1.0$)$ & 21.1 (9.0 to 41.7$)$ & 99.0 (98.7 to 99.3$)$ \\
\hline & $\geq 60$ years & $13.8(6.1$ to 31.1$)$ & 0.78 (0.6 to 1.0$)$ & 20.7 (10.4 to 37.0$)$ & 98.5 (98.2 to 98.8$)$ \\
\hline & Overall & 21.9 (13.6 to 35.4$)$ & 0.71 (0.6 to 0.8$)$ & 20.5 (13.8 to 29.4 ) & 99.2 (99.0 to 99.3 ) \\
\hline \multirow[t]{4}{*}{ Overall alarm features } & $<50$ years & 5.02 (3.8 to 6.6 ) & $0.20(0.06$ to 0.7$)$ & 3.0 (2.3 to 3.8$)$ & 99.9 (99.6 to 100$)$ \\
\hline & $50-60$ years & 4.34 (3.4 to 5.6$)$ & 0.22 (0.08 to 0.6$)$ & 5.6 (4.4 to 7.0$)$ & 99.7 (99.2 to 99.9$)$ \\
\hline & $\geq 60$ years & 3.10 (2.6 to 3.6$)$ & $0.16(0.06$ to 0.5$)$ & 5.5 (4.7 to 6.4$)$ & 99.7 (99.1 to 99.9) \\
\hline & Overall & 4.10 (3.6 to 4.6$)$ & $0.18(0.10$ to 0.3$)$ & 4.7 (4.2 to 5.2$)$ & 99.8 (99.6 to 99.9$)$ \\
\hline
\end{tabular}

The PLR, NLR, PPV and NPV of individual alarm feature were calculated to discriminate between dyspeptic patients with and without upper GI malignancies.

The histopathological examination from endoscopic biopsy or surgical specimens with diagnosing upper GI malignancies served as the reference group.

GI, gastrointestinal; NLR, negative likelihood ratio; NPV, negative predictive value; PLR, positive likelihood ratio; PPV, positive predictive value.

grading of gastroduodenitis. Benefits include using the endoscopic results to clarify therapy, relieve anxiety and reduced healthcare utilisation, which suggests important and unmeasured contributions of endoscopy. Among patients with dyspepsia who underwent endoscopy, 35.3\% were younger than 50 years of age and had no alarm features. The low prevalence of UGI malignancy and other serious pathology in young patients without alarm features is consistent with previous reports. ${ }^{20-22}$ Uncomplicated oesophagitis and peptic ulcer disease were found in $11.2 \%$ of this subgroup. Treatment for young patients without alarm symptoms may be empiric and may not require endoscopy. In our analysis, Barrett's oesophagus was found in only $0.5 \%$ of patients among all age groups of dyspeptic patients, similar to other reported endoscopic results in the general population but lower than in

Table 6 Diagnostic performance of alarm features for predicting upper Gl malignancies among patients with previous or current smoking

\begin{tabular}{lllll}
\hline Alarm features & PLR $(\mathbf{9 5 \%} \mathbf{C l})$ & NLR $(\mathbf{9 5 \%} \mathbf{C l})$ & PPV (95\% Cl) & NPV (95\% CI) \\
\hline Dysphagia & $15.2(3.34$ to 69.1$)$ & $0.81(0.59$ to 1.11$)$ & $28.6(8.1$ to 64.5$)$ & $97.9(97.2$ to 98.5$)$ \\
Weight loss & $5.07(4.14$ to 6.21$)$ & 0.00 & $11.8(9.8$ to 14.0$)$ & 100.0 \\
Gl bleeding/anaemia & $8.16(4.40$ to 15.2$)$ & $0.43(0.20$ to 0.92$)$ & $17.6(10.3$ to 28.5$)$ & $98.9(97.6$ to 99.5$)$ \\
Persistent vomiting & $16.3(4.92$ to 54.0$)$ & $0.71(0.48$ to 1.07$)$ & $30.0(11.5$ to 58.7$)$ & $98.2(97.3$ to 98.8$)$ \\
Overall alarm features & $3.97(3.34$ to 4.72$)$ & 0.00 & $9.4(8.1$ to 11.0$)$ & 100.0 \\
\hline
\end{tabular}

The PLR, NLR, PPV and NPV of individual alarm feature were calculated to discriminate between dyspeptic patients with and without upper GI malignancies.

The histopathological examination from endoscopic biopsy or surgical specimens with diagnosing upper GI malignancies served as the reference group.

GI, gastrointestinal; NLR, negative likelihood ratio; NPV, negative predictive value; PLR, positive likelihood ratio; PPV, positive predictive value. 
GERD patients. ${ }^{23}$ It is noteworthy that alarm features were not predictive of Barrett's oesophagus (data not shown).

In our study, the prevalence of UGI cancer $(1.2 \%)$ was similar to that reported from a study conducted in Taiwan ${ }^{8}$ but much lower than those reported from studies conducted in China and Iran. ${ }^{10}{ }^{12}$ The differences between and among studies may be due to differences in the background prevalence of $H$. pylori infection in the studied populations. ${ }^{24-26}$ We also found a positive association between cancer frequency and increasing age, which was similarly found in a Chinese and a Singaporean study. ${ }^{1027}$ Accordingly, international guidelines recommend UGI endoscopy for routine investigation of dyspepsia when patients are aged 55 years and older. The American College of Gastroenterology (ACG) and the Canadian Association of Gastroenterology (CAG) guidelines on dyspepsia have raised this age threshold to 60 years. ${ }^{4}$ This recommendation was made based on the results of a cost-effectiveness analysis. However, it remains controversial whether these guidelines can be applied to other parts of the world where the disease patterns, the prevalence of malignancy, and the healthcare systems are different. For example, a primary concern relating to the use of endoscopy in Asian dyspeptic patients is a higher prevalence and a younger age at the onset of UGI cancer among Asians. In our study, approximately $53 \%$ of cancer patients $(29 / 55)$ were aged less than 60 years, and these patients would be missed if the ACG/CAG guideline were applied in Thailand. Therefore, the age threshold for endoscopy in Thai patients with dyspepsia should differ from those recommended in Western countries.

The age threshold for endoscopic investigation of uncomplicated dyspepsia also differs among different regions in Asia. In Hong Kong, $10 \%$ of patients with gastric cancer are aged less than 45 years. Sung et al reported that among 2918 patients with dyspepsia, gastric cancer was found in 3 patients $(0.1 \%)$ aged less than 45 years, and none of them had alarm features. ${ }^{7}$ This study raises concerns about the safety of the 'test-and-treat' strategy for managing patients with dyspepsia in Asia. In Taiwan, the relative frequency of patients with gastric cancer was 1.8 and 1.02 cases per 1000 endoscopies for uninvestigated dyspepsia in patients aged $<45$ and $<40$ years, respectively. ${ }^{8}$ Therefore, an age threshold of 40 years was recommended for patients with dyspepsia in Taiwan. More recently, an endoscopic database review of $>100000$ Chinese patients ${ }^{10}$ showed a $4.2 \%$ prevalence of UGI malignancies, higher than the $0.9 \%$ prevalence reported from Hong $\mathrm{Kong}^{7}$ and the $1.25 \%$ prevalence reported from Taiwan. ${ }^{8}$ The prevalence of malignancy increased from $0.6 \%$ in patients aged $<35$ years to $18.0 \%$ in patients aged $>75$ years in the Chinese population. ${ }^{10}$ Those investigators suggested that prompt endoscopy should be recommended in Chinese patients with uninvestigated dyspepsia and a high background prevalence of $H$. pylori infection because age had limited predictive value for potential malignancy. In contrast, our analysis showed a relatively low $(0.35 \%)$ prevalence of UGI malignancy among patients younger than 45 years, and none of those patients were aged less than 40 years. Since UGI malignancy was detected in two patients $(0.04 \%)$ aged under 50 years and neither had alarm symptoms, prompt endoscopy only in dyspeptic patients aged $\geq 50$ years or those with alarm features would have missed cancer detection in these patients. Hence, starting endoscopy at an age threshold of 50 years might be appropriate in Thai patients presenting with dyspepsia regardless of alarm features.

The presence of alarm features has been a major determinant in prioritising the initial endoscopic evaluation of patients presenting with dyspepsia because it is generally believed that these factors indicate a higher probability of malignancy. Based on the area under the ROC, our analysis showed that individual alarm features have poor accuracy for detecting UGI malignancy because patients with benign UGI disease or carcinoma of the colon also present with these features. Thus, investigation of the colon should be considered in such cases with alarm features unexplained by upper endoscopy or concomitant intestinal symptoms. The sensitivity for predicting malignancy was less than $50 \%$ for individual alarm features, except for unexplained weight loss. The PPV of persistent vomiting for malignancy was somewhat better than the other alarm features. Our findings are consistent with those from a systematic review and meta-analysis of more than 4000 dyspeptic patients with a low reported prevalence of UGI malignancy $(0.8 \%)$ that showed low pooled sensitivity and specificity of individual alarm features of $67 \%$ (95\% CI $54 \%$ to $83 \%$ ) and $66 \%$ (95\% CI $55 \%$ to $79 \%$ ), respectively. ${ }^{15}$ It should be noted, however, that heterogeneity existed among the results of included studies. In the Chinese population with a high background prevalence of UGI cancer, the total sensitivity of alarm features was only $13.4 \%(12.9 \%-13.9 \%) .{ }^{10}$ Another meta-analysis of the Asian population with dyspepsia that consisted mainly of Chinese and Indian populations with UGI malignancy rates $(1.3 \%)$ comparable to that found in our study also reported limited value of alarm features for predicting UGI malignancy with a sensitivity of approximately $50 \%{ }^{16}$

Among the four-alarm features, unexplained weight loss had the highest sensitivity (80\%), dysphagia had the lowest sensitivity $(11 \%)$, and the other two features had intermediate sensitivity. All of these alarm features had very high specificity and NPVs. These results may reflect the low prevalence of cancer in our cohort, but not any specific attribute of any alarm feature for excluding malignancy. However, when calculating the PLR and NLR of these alarm features, we found that persistent vomiting, dysphagia, and GI bleeding among patients aged less than 50 years had a PLR $>10$, which was strongly associated with possible malignancy. Similarly, dysphagia and persistent vomiting had a PLR $>10$ for predicting UGI cancer in previous or active smokers, regardless of age. This finding should help guide the management of patients with dyspepsia via the use of individual alarm features based 
on age and unhealthy lifestyle as a screening tool for upper endoscopy. Because cancer prevalence is rare in younger individuals who do not have alarm features, this strategy may give more meaningful guidance to primary care providers.

\section{Limitations}

This study has some limitations. First, although patients who had previously undergone imaging studies highly suspected of having UGI malignancy and those who had indefinite biopsy results on prior endoscopic examination were excluded from this study, there might have been some selection bias. Since our study was conducted at a tertiary, referred centre, this could lead to biased estimates of the prevalence of malignancies and other organic causes of dyspepsia. Certain individuals may be referred to our centre for endoscopy due to refractory dyspepsia that does not respond to medical therapy. Second, about onefifth of patients who underwent endoscopy for dyspepsia were younger than 40 years of age. A possible explanation for this may be that young people with no alarm features may be less likely to undergo endoscopy. This could affect the diagnostic value of the age threshold for predicting UGI malignancy among patients with dyspepsia. However, the impact on both specificity and NPV was not substantial because all of those patients were free of malignancy. Finally, even though the family history of gastric cancer is a strong reported risk factor, ${ }^{28}$ none of our malignant cases had a family history of UGI cancer. However, the finding should be interpreted with caution because data gathered from medical records tend to underestimate clinical features. Our study found a link between UGI cancers and smoking. The findings might imply that environmental factors, such as cigarette smoking, rather than genetic factors, play a significant role in carcinogenesis among our population.

\section{Conclusion}

This study provides relevant data to warrant an endoscopic assessment in dyspeptic patients in the area with a low prevalence of $H$. pylori infection and UGI malignancies and limited resources. The overall value of age and alarm features for detecting malignancies was shown to be limited. Therefore, a blanket policy of using a specific age cut-off or alarm features as the indications for endoscopy may not be a suitable strategy in the areas where resources are restricted. Alarm features, including persistent vomiting, dysphagia and GI bleeding/anaemia, were shown to be strong predictors of underlying malignancy in patients aged $<50$ years, so endoscopic evaluation in these patients is indicated. Without these alarm symptoms, cancer prevalence is negligible in this age group; thus, medical treatment can be initiated without endoscopy referral. However, further studies are needed to establish a pre-endoscopy risk score based on age, alarm features and novel risk factors for determining patients with underlying UGI cancer.
Contributors PC designed the study. UKao and PC participated in the data collection and analysis. Ukao drafted the manuscript. PC, NP, JL, MM, SL and UKac made the critical revision. All authors interpreted the data and approved the final manuscript. PC is the guarantor of the article.

Funding This study was funded by a grant from the Siriraj Research Development Fund of the Faculty of Medicine Siriraj Hospital, Mahidol University, Bangkok, Thailand (Grant no. N/A).

Disclaimer The aforementioned funding agency had no influence on the interpretation of data, the conclusions drawn, or the decision to publish.

Competing interests None declared.

Patient and public involvement Patients and/or the public were not involved in the design, or conduct, or reporting, or dissemination plans of this research.

Patient consent for publication Not applicable.

Ethics approval The study protocol was approved by the Siriraj Institutional Review Board (SIRB) (COA no. Si473/2011).

Provenance and peer review Not commissioned; externally peer reviewed. Data availability statement № data are available.

Open access This is an open access article distributed in accordance with the Creative Commons Attribution Non Commercial (CC BY-NC 4.0) license, which permits others to distribute, remix, adapt, build upon this work non-commercially, and license their derivative works on different terms, provided the original work is properly cited, appropriate credit is given, any changes made indicated, and the use is non-commercial. See: http://creativecommons.org/licenses/by-nc/4.0/.

\section{ORCID iDs}

Uayporn Kaosombatwattana http://orcid.org/0000-0001-8076-1659

Phunchai Charatcharoenwitthaya http://orcid.org/0000-0002-8334-0267

Nonthalee Pausawasdi http://orcid.org/0000-0002-3737-8555

\section{REFERENCES}

1 Ford AC, Marwaha A, Sood R, et al. Global prevalence of, and risk factors for, uninvestigated dyspepsia: a meta-analysis. Gut 2015;64:1049-57.

2 Kachintorn U. Epidemiology, approach and management of functional dyspepsia in Thailand. $J$ Gastroenterol Hepatol 2011;26:32-4.

3 Pittayanon R, Leelakusolvong S, Vilaichone R-K, et al. Thailand dyspepsia guidelines: 2018. J Neurogastroenterol Motil 2019;25:15-26.

4 Moayyedi P, Lacy BE, Andrews CN, et al. ACG and CAG clinical guideline: management of dyspepsia. Am J Gastroenterol 2017;112:988-1013.

5 Talley NJ, Lam SK, Goh KL, et al. Management guidelines for uninvestigated and functional dyspepsia in the Asia-Pacific region: first Asian Pacific Working Party on functional dyspepsia. J Gastroenterol Hepatol 1998;13:335-53.

6 Wallace MB, Durkalski VL, Vaughan J, et al. Age and alarm symptoms do not predict endoscopic findings among patients with dyspepsia: a multicentre database study. Gut 2001;49:29-34.

7 Sung JJ, Lao WC, Lai MS, et al. Incidence of gastroesophageal malignancy in patients with dyspepsia in Hong Kong: implications for screening strategies. Gastrointest Endosc 2001;54:454-8.

8 Liou J-M, Lin J-T, Wang H-P, et al. The optimal age threshold for screening upper endoscopy for uninvestigated dyspepsia in Taiwan, an area with a higher prevalence of gastric cancer in young adults. Gastrointest Endosc 2005;61:819-25.

9 Sumathi B, Navaneethan U, Jayanthi V. Appropriateness of indications for diagnostic upper gastrointestinal endoscopy in India. Singapore Med J 2008;49:970-6.

10 Bai Y, Li Z-S, Zou D-W, et al. Alarm features and age for predicting upper gastrointestinal malignancy in Chinese patients with dyspepsia with high background prevalence of Helicobacter pylori infection and upper gastrointestinal malignancy: an endoscopic database review of 102,665 patients from 1996 to 2006. Gut 2010;59:722-8.

11 Hsu Y-C, Yang T-H, Liou J-M, et al. Can clinical features stratify use of endoscopy for dyspeptic patients with high background prevalence of upper gastrointestinal cancer? Dig Liver Dis 2012;44:218-23.

12 Khademi H, Radmard A-R, Malekzadeh F, et al. Diagnostic accuracy of age and alarm symptoms for upper GI malignancy in patients with 
dyspepsia in a GI clinic: a 7-year cross-sectional study. PLoS One 2012;7:e39173.

13 Uehara G, Nago A, Espinoza R, et al. [Optimal age for gastric cancer screening in patients with dyspepsia without alarm symptoms]. Rev Gastroenterol Peru 2007;27:339-48.

14 Vakil N, Talley N, van Zanten SV, et al. Cost of detecting malignant lesions by endoscopy in 2741 primary care dyspeptic patients without alarm symptoms. Clin Gastroenterol Hepatol 2009;7:756-61.

15 Vakil N, Moayyedi P, Fennerty MB, et al. Limited value of alarm features in the diagnosis of upper gastrointestinal malignancy: systematic review and meta-analysis. Gastroenterology 2006;131:390-401.

16 Chen SL, Gwee KA, Lee JS, et al. Systematic review with metaanalysis: prompt endoscopy as the initial management strategy for uninvestigated dyspepsia in Asia. Aliment Pharmacol Ther 2015;41:239-52.

17 Fock KM, Ang TL. Epidemiology of Helicobacter pylori infection and gastric cancer in Asia. J Gastroenterol Hepatol 2010;25:479-86.

18 Stanghellini V, Chan FKL, Hasler WL, et al. Gastroduodenal disorders. Gastroenterology 2016;150:1380-92.

19 Lundell LR, Dent J, Bennett JR, et al. Endoscopic assessment of oesophagitis: clinical and functional correlates and further validation of the Los Angeles classification. Gut 1999;45:172-80.
20 Abdeljawad K, Wehbeh A, Qayed E. Low prevalence of clinically significant endoscopic findings in outpatients with dyspepsia. Gastroenterol Res Pract 2017;2017:3543681

21 Canga C, Vakil N. Upper GI malignancy, uncomplicated dyspepsia, and the age threshold for early endoscopy. Am J Gastroenterol 2002;97:600-3.

22 Delaney BC, Wilson S, Roalfe A, et al. Cost effectiveness of initial endoscopy for dyspepsia in patients over age 50 years: a randomised controlled trial in primary care. Lancet 2000;356:1965-9.

23 Marques de Sá I, Marcos P, Sharma P, et al. The global prevalence of Barrett's esophagus: a systematic review of the published literature. United European Gastroenterol J 2020;8:1086-105.

24 Vilaichone R-K, Gumnarai P, Ratanachu-Ek T, et al. Nationwide survey of Helicobacter pylori antibiotic resistance in Thailand. Diagn Microbiol Infect Dis 2013;77:346-9.

25 Xu C, Yan M, Sun Y, et al. Prevalence of Helicobacter pylori infection and its relation with body mass index in a Chinese population. Helicobacter 2014;19:437-42.

26 Yim JY, Kim N, Choi SH, et al. Seroprevalence of Helicobacter pylori in South Korea. Helicobacter 2007;12:333-40.

27 Wai CT, Yeoh KG, Ho KY, et al. Diagnostic yield of upper endoscopy in Asian patients presenting with dyspepsia. Gastrointest Endosc 2002;56:548-51.

28 Yaghoobi M, Bijarchi R, Narod SA. Family history and the risk of gastric cancer. Br J Cancer 2010;102:237-42. 